International Journal of Research in Advent Technology, Vol.7, No.4, April 2019

E-ISSN: 2321-9637

Available online at www.ijrat.org

\title{
Comparison of Various B20 Biodiesel Blends in Diesel Engines
}

\author{
P.A.Harari ${ }^{1}$, A.J.Deokar ${ }^{2}$, A.S.Sutar ${ }^{3}$, A.K.Patil ${ }^{4}$, S.D.Patil ${ }^{5}$, S.S.Patil ${ }^{6}$ \\ ${ }_{1,2}$ Assistant Professor, ${ }^{3,4,5,6}$ B.E Final Year Students \\ Department of Mechanical Engineering, Sant Gajanan Maharaj College of Engineering, Mahagaon, India \\ hararipraveen@gmail.com
}

\begin{abstract}
In the present study, comparative study had been carried out to analyze the performance and emission characteristics of compression ignition engine fuelled with B20 blends of Karanja, Jatropha, Thevetia Peruviana, Mahua and Neem biodiesel. The engine tests are conducted on Kirloskar, 5.2 kW, 4-Stroke, Single cylinder, 1500 rpm, Water cooled, Direct injection, Diesel engine with eddy current dynamometer. In this work we used injection timing $23^{\circ} \mathrm{BTDC}$ and injection pressure 210 bar. From the test results, it could be observed that among different fuels Karanja B20 blend showed very close performance with the neat diesel.
\end{abstract}

Keywords- Karanja, Jatropha, Thevetia Peruviana, Mahua, Neem, Blends, Emission, Engine, Performance.

\section{INTRODUCTION}

Due to the gradual depletion of world petroleum reserves and the impact of environmental pollution of increasing exhaust emissions, there is an urgent need for suitable alternative fuels for use in diesel engines. In view of this, vegetable oil is a promising alternative because it has several advantages; it is renewable, environmentally friendly and produced easily in rural areas, where there is an acute need for modern forms of energy [1]. The use of non-edible vegetable oils compared to edible oils is very significant because of the tremendous demand for edible oils as food and they are far too expensive to be used as fuel at present. Rapid increase in the prices of petroleum products and harmful exhaust emissions from engines jointly created renewed interest among researchers to find the suitable alternative fuels [2]. It is concluded that the use of any vegetable oil possess some problems when subjected to prolonged usage in internal combustion engines. These problems are attributed to high viscosity, low volatility of neat vegetable oils [3] High viscosity of vegetable oil causes some problems in atomization by injector systems and combustion in cylinders of diesel engines. Some of the common problems in the long run are coking and trumpet formation on the injectors, carbon deposits, oil ring sticking and gelling of lubricating oil as a result of contamination by the vegetable oils [4]. There are different methods for reducing viscosity of vegetable oils such as preheating, blending and transesterification. As the edible oil prices are escalating day by day so that researchers are working on non-edible oils [5]. These plants grow almost throughout India. The oil content is approximately $40 \%$. These plants found in India, in a semi wild condition near villages. These plants can grow rapidly almost anywhere even on gravelly, sandy and saline soils [6].

Yadav et al. [1] conducted experiments on, performance of diesel engine using blends of conventional diesel and Jatropha biodiesel as alternative fuel for clean environment. Results showed that, as the load increases, BTE increases for all the fuel samples tested including diesel up to $80 \%$ of rated engine load for all the fuel samples. The maximum value of efficiency has been found for JB20 fuel sample as $28.14 \%$ which was $4.26 \%$ higher than diesel for $80 \%$ of rated engine load. The BTE of JB100 sample was observed to be lower than conventional diesel for the entire brake load.

Venkatraman et al. [2] conducted experiments on, performance and exhaust emissions of a low heat rejection diesel engine using Jatropha oil as fuel. Results showed that, the BTE was lower with raw Jatropha oil as compared to diesel. The maximum BTE with raw Jatropha oil was about $22.54 \%$ whereas it was $24.43 \%$ with diesel at $75 \%$ load condition. The BTE was higher with methyl ester of Jatropha oil and 30\% Kerosene blend compared to raw Jatropha oil. The values were $23.89 \%$ and $23.40 \%$ respectively.

Mamilla et al. [3] conducted experiments on, effect of combustion chamber design on a DI diesel engine fuelled with Jatropha methyl esters blends with diesel. Results showed that, BTE was slightly lower for methyl esters and their blends compared to diesel at all loads. At rated power $(4.4 \mathrm{~kW})$ the BTE of diesel, 20\% JTME, 40\% JTME, 60\% JTME, 80\% JTME and JTME were $33.36 \%, 32.8 \%, 31.6 \%$, $31.22 \%, 30.87 \%$ and $29.37 \%$ respectively. 
International Journal of Research in Advent Technology, Vol.7, No.4, April 2019

$$
\text { E-ISSN: 2321-9637 }
$$

\section{Available online at www.ijrat.org}

Agarwal et al. [4] conducted experiments on, process optimization for biodiesel production from Jatropha oil and its performance evaluation in a CI engine. Results showed that, BTE was higher for JB100 for all brake mean effective pressures.

Venkatesan et al. [5] conducted experiments on, effect of injection timing and injection pressure on a single cylinder diesel engine for better performance and emission characteristics for Jatropha biodiesel in single and dual fuel mode with CNG. Results showed that, BTE for diesel baseline at 180 bar pressure $27^{\circ}$ bTDC was $13.75 \%$ and $28 \%$ at low and high loads of operation respectively.

\section{Karanja}

Karanja is a fast-growing, multipurpose tree of the humid tropic. With the increasing production of oil for biofuel, large amounts of oil cake are available for livestock feeding. Karanja is the popular name of Millettia pinnata in Hindi while it is called Pongam in Tamil. Karanja is a medium sized evergreen or briefly deciduous tree, usually about 8 $\mathrm{m}$ high but that can grow to $15-25 \mathrm{~m}$. The trunk is straight or crooked, $50 \mathrm{~cm}$ in diameter, covered with grey to greyish brown bark, smooth or vertically fissured. Karanja has a deep and thick taproot with several secondary lateral roots. The branches are spreading or dropping and form a broad hemispherical crown of dark green leaves. Branchlets are hairless with pale stipule scars. Leaves are alternate, pinnately compound, pinkish-red when young becoming glossy dark green at maturity. The leaves consist of 5 to 7 glabrous leaflets borne in pairs on slender stalks, and a single end leaf. The leaflets are ovate-elliptical, about 5-10 cm long and 4-6 cm wide, pointed at the tip. The flowers are lavender, pink white in colour, finely pubescent, and 15-18 mm long. Fruits are numerous, elliptical, 3-6 $\mathrm{cm}$ long x 2-3 cm broad, hard and woody indehiscent pods. Pods contain 1-2 seeds. Seeds are bean-like, $1.5-2.5 \mathrm{~cm}$ long $x$ 1.2-2.0 $\mathrm{cm}$ wide, dark brown in colour. They are oily, containing about $30-40 \%$ oil. The tree sheds its pods which produce long lasting ground litter. The seeds germinate after the pod husks decay, several months after dropping.

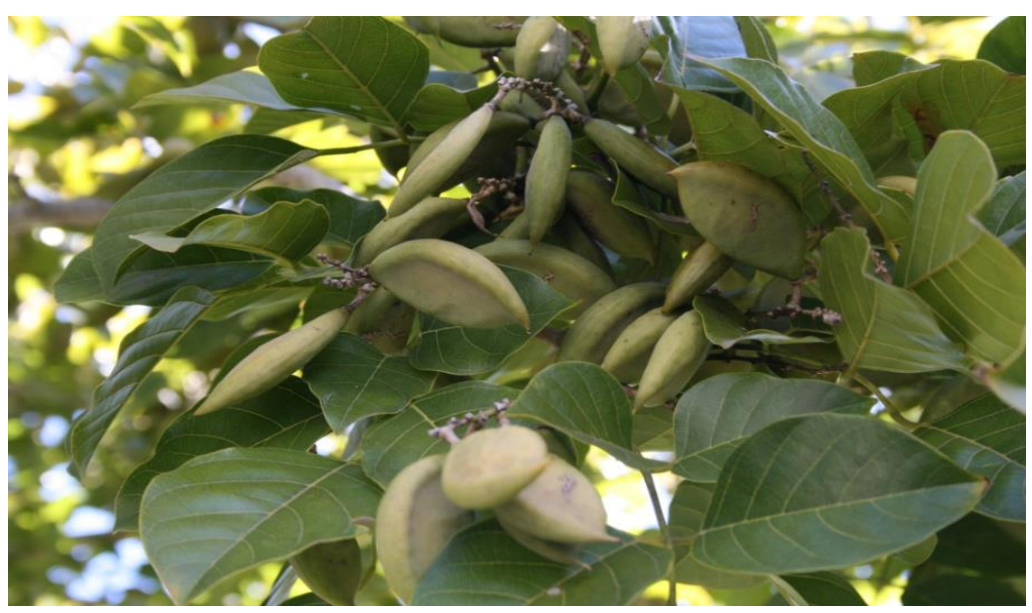

Fig. 1. Karanja

\section{Jatropha}

Jatropha oil is produced from the seeds of the Jatropha curcas, a plant that can grow in wastelands across India, and the oil is considered to be an excellent source of biodiesel. India is keen on reducing its dependence on coal and petroleum to meet its increasing energy demand and encouraging Jatropha cultivation is a crucial component of its energy policy. Large plots of waste land have been selected for Jatropha cultivation and will provide much needed employment to the rural poor of India. Businesses are also seeing the planting of Jatropha as a good business opportunity. The Government of India has identified 400,000 square kilometers of land where Jatropha can be grown, hoping it will replace $20 \%$ of India's diesel consumption by 2011. Life-cycle analysis studies have shown favorable energy balance for production of Jatropha based biodiesel in India and also a potential GHG emission saving of $33-42 \%$ compared to fossil-based diesel. Jatropha curcas is a poisonous, semievergreen shrub or small tree, reaching a height of $6 \mathrm{~m}$. 


\section{Available online at www.ijrat.org}

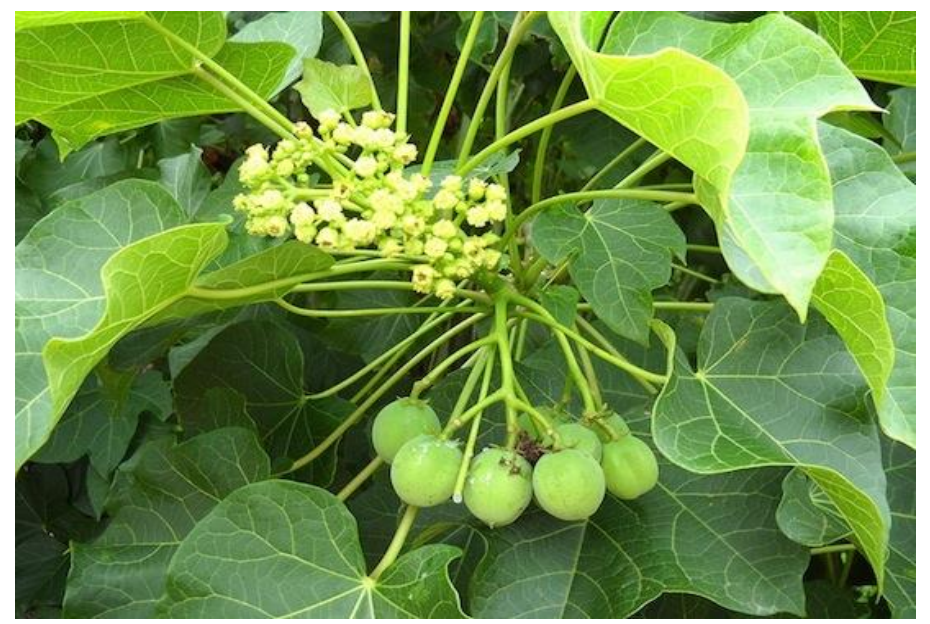

Fig. 2. Jatropha

\section{Thevetia Peruviana}

Mexican oleander is a large shrub or a small tree, up to 10 to 20 feet tall with Oleander-like leaves mostly in whorls of three, long and narrow up to 10 inches long. Tip of leafs are pointed with a dark green color. Flowers are generally yellow, but there are varieties with white and orange flowers too. Fruit is small, containing two to four flat seeds. If ingested may experience pain in the mouth and lips, may also develop vomiting, cramping, abdominal pain, nausea and bradycardia shortly after ingestion. Mexican oleander is native to tropical America. Cascabela thevetia is an evergreen tropical shrub or small tree. Its leaves are willow-like, linear-lanceolate, and glossy green in color.
They are covered in waxy coating to reduce water loss. Its stem is green turning silver/gray as it ages. Flowers bloom from summer to fall. The long funnel-shaped sometimesfragrant yellow flowers are in few-flowered terminal clusters. Its fruit is deep red-black in color encasing a large seed that bears some resemblance to a Chinese lucky nut. Cascabela thevetia is commonly known as Kaneir in Hindi language in India. It is effectively drought resistant and tolerant to high temperatures, hence found in various states of India like Bihar, Delhi, Gujarat, Madhya Pradesh, Rajasthan, Tamil Nadu and Uttar Pradesh where semi-arid climate is prevalent.

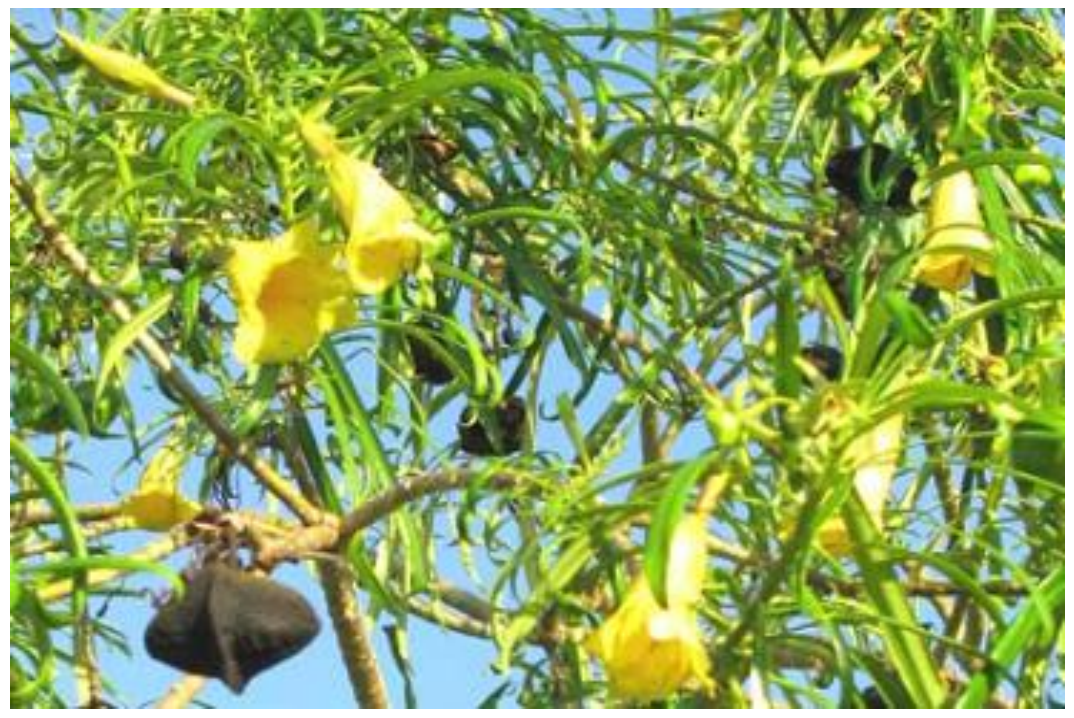

Fig. 3. Thevetia Peruviana 


\section{International Journal of Research in Advent Technology, Vol.7, No.4, April 2019 E-ISSN: 2321-9637 \\ Available online at www.ijrat.org}

Mahua

Mahua longifolia is an Indian tropical tree found largely in the central and north Indian plains and forests. It is commonly known as mahuwa, mahua, mahwa, mohulo, or vippa chettu. It is a fast-growing tree that grows to approximately 20 meters in height, possesses evergreen or semi-evergreen foliage, and belongs to the family Sapotaceae. It is adaptable to arid environments, being a prominent tree in tropical mixed deciduous forests in India in the states of West Bengal, Chhattisgarh, Jharkhand, Uttar Pradesh, Bihar, Maharashtra, Telangana, Madhya Pradesh, Kerala, Gujarat, Odisha and Tamil Nadu. It is cultivated in warm and humid regions for its oleaginous seeds producing between 20 and $200 \mathrm{~kg}$ of seeds annually per tree, depending on maturity, flowers and wood. The fat is used for the care of the skin, to manufacture soap or detergents, and as a vegetable butter. It can also be used as a fuel oil. The seed cakes obtained after extraction of oil constitute very good fertilizer. The flowers are used to produce an alcoholic drink in tropical India. This drink is also known to affect the animals. Several parts of the tree, including the bark, are used for their medicinal properties. It is considered holy by many tribal communities because of its usefulness. The tree is considered a boon by the native tribes who are forest dwellers and keenly conserve this tree. However, conservation of this tree has been marginalised, as it is not favoured by non-native tribes.

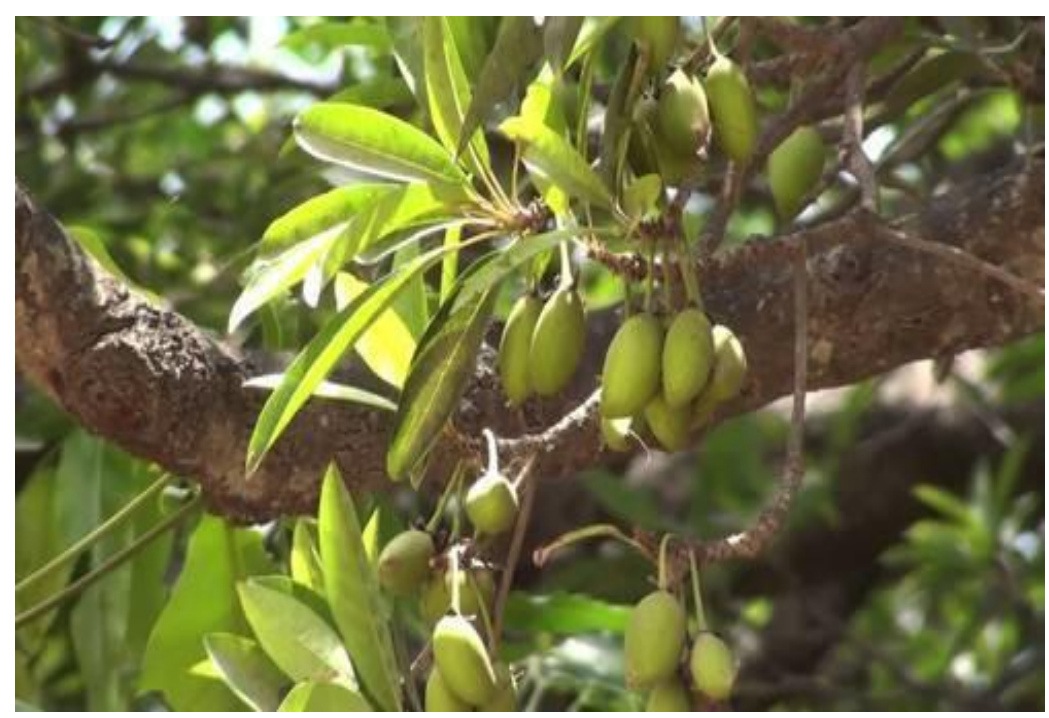

Fig. 4. Mahua

\section{Neem}

Azadirachta indica, commonly known
as neem, nimtree or Indian lilac, is a tree in the mahogany family Meliaceae. It is one of two species in the genus Azadirachta, and is native to the Indian subcontinent, i.e. India, Nepal, Pakistan, Bangladesh, Sri Lanka and Maldives. It is typically grown in tropical and semi-tropical regions. Neem trees also grow in islands located in the southern part of Iran. Its fruits and seeds are the source of neem oil. Neem is a fast-growing tree that can reach a height of 15-20 metres (49-66 ft), and rarely 35-40 metres (115-131 ft). It is evergreen, but in severe drought it may shed most of its leaves or nearly all leaves. The branches are wide and spreading. The fairly dense crown is roundish and may reach a diameter of 2025 metres (66-82 ft). The opposite, pinnate leaves are 20-
40 centimetres (7.9-15.7 in) long, with 20 to 31 medium to dark green leaflets about 3-8 centimetres (1.2-3.1 in) long. The terminal leaflet often is missing. The petioles are short. The flowers are arranged in moreor-less drooping axillary panicles which are up to 25 centimetres (9.8 in) long. An individual flower is 5-6 millimetres (0.20-0.24 in) long and 8-11 millimetres (0.31-0.43 in) wide. The fruit is a smooth (glabrous), olive-like drupe which varies in shape from elongate oval to nearly roundish, and when ripe is $1.4-2.8$ centimetres (0.55-1.10 in) by $1.0-1.5$ centimetres (0.39-0.59 in). The fruit skin (exocarp) is thin and the bitter-sweet pulp (mesocarp) is yellowish-white and very fibrous. The white, hard inner shell (endocarp) of the fruit encloses one, rarely two, or three, elongated seeds (kernels) having a brown seed coat. 


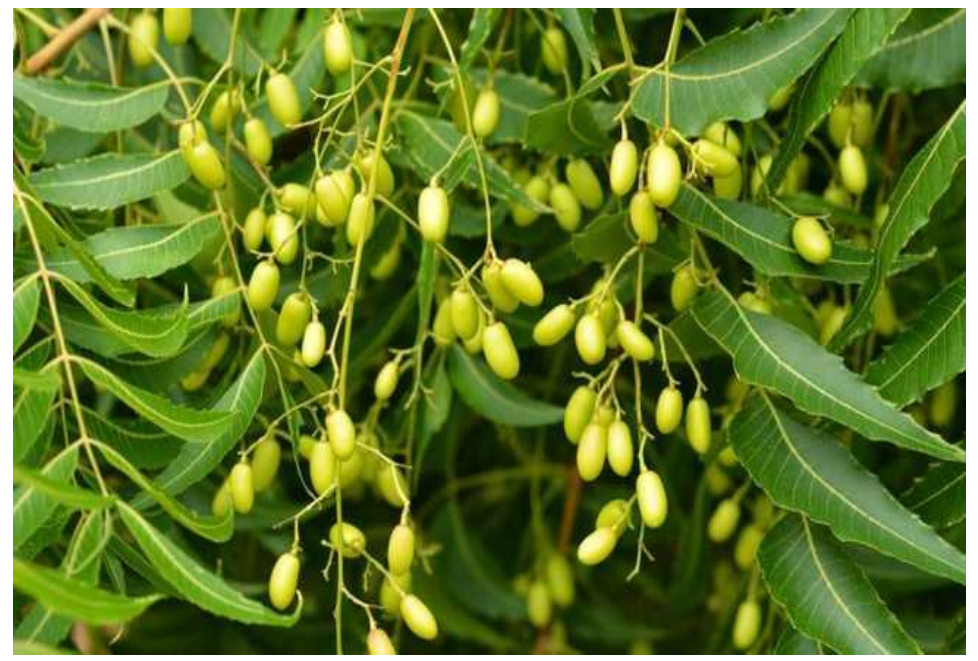

Fig. 5. Neem

\subsection{Objectives}

* To study Jatropha B20, Thevetia Peruviana B20, Karanja B20, Mahua B20, Neem B20 blends in single cylinder diesel engine as an alternative fuel.

* To study the performance and emission characteristics of diesel engine.

* To study the best suitable B20 blend for existing engine in terms of performance and emissions.

\subsection{Methodology}

- Collection of raw oil of Jatropha, Thevetia Peruviana, Karanja, Mahua and Neem.

* Transesterification reaction to convert raw oil into biodiesel.

* Prepare blends with diesel such as B20.

* Determine fuel properties such as Density, Kinematic viscosity, Flash point, Fire point, Calorific value.

* Single Cylinder, Water Cooled, 4-Stroke, 1500 RPM, $5.2 \mathrm{~kW}, 230$ bar Injection Pressure, $23^{\circ}$ BTDC Injection Timing, Hemispherical Combustion Chamber, 3 Hole Nozzle, 17.5:1 Compression Ratio engine is used for the study.

* Determine performance and emission characteristics Brake Thermal Efficiency, Brake Specific Fuel Consumption, Total Fuel Consumption, HC, CO, NOx, Smoke emissions.

* Compare the results and find the optimum B20 blend for engine.
2. TRANSESTERIFICATION REACTION

It is most commonly used and important method to reduce the viscosity of vegetable oils. In this process triglyceride reacts with three molecules of alcohol in the presence of a catalyst producing a mixture of fatty acids, alkyl ester and glycerol. The process of removal of all the glycerol and the fatty acids from the vegetable oil in the presence of a catalyst is called esterification. The parameter such as temperature, molar ratio and catalyst concentration that affect the transesterification of raw oil were optimized initially. The transesterification set up houses 2 L capacity, round bottom flask provided with three necks that was placed in a water container for heating the oil. A heater with a temperature regulator was placed in the round bottom flask. A high speed motor with a magnetic stirrer was used for vigorous mixing of the oil. In the transesterification process triglycerides of raw oil reacts with methyl alcohol in the presence of catalyst $(\mathrm{NaOH})$ to produce a fatty acid ester and glycerol. In this process $1000 \mathrm{~g}$ raw oil, $230 \mathrm{~g}$ methanol and $8 \mathrm{~g}$ sodium hydroxide pellets were placed in the round bottom flask. The contents were heated to $70^{\circ} \mathrm{C}$ and stirred vigorously for one hour to promote ester formation. The mixture was next transferred to a separating funnel and allowed to settle under gravity overnight. The upper layer in the separating funnel consists of ester whist the lower layer is glycerol which was removed. The separated ester with $250 \mathrm{~g}$ hot water and allowed to settle under gravity for 24 hours. Water washing separates residual fatty acids and catalyst and these were removed using a separating 
International Journal of Research in Advent Technology, Vol.7, No.4, April 2019

E-ISSN: 2321-9637

Available online at www.ijrat.org

funnel. Finally the moisture from the ester was removed by adding silica gel crystals. Various

biodiesel-diesel blends B10, B20, B30, B40 and B50 were prepared for the experimental work.
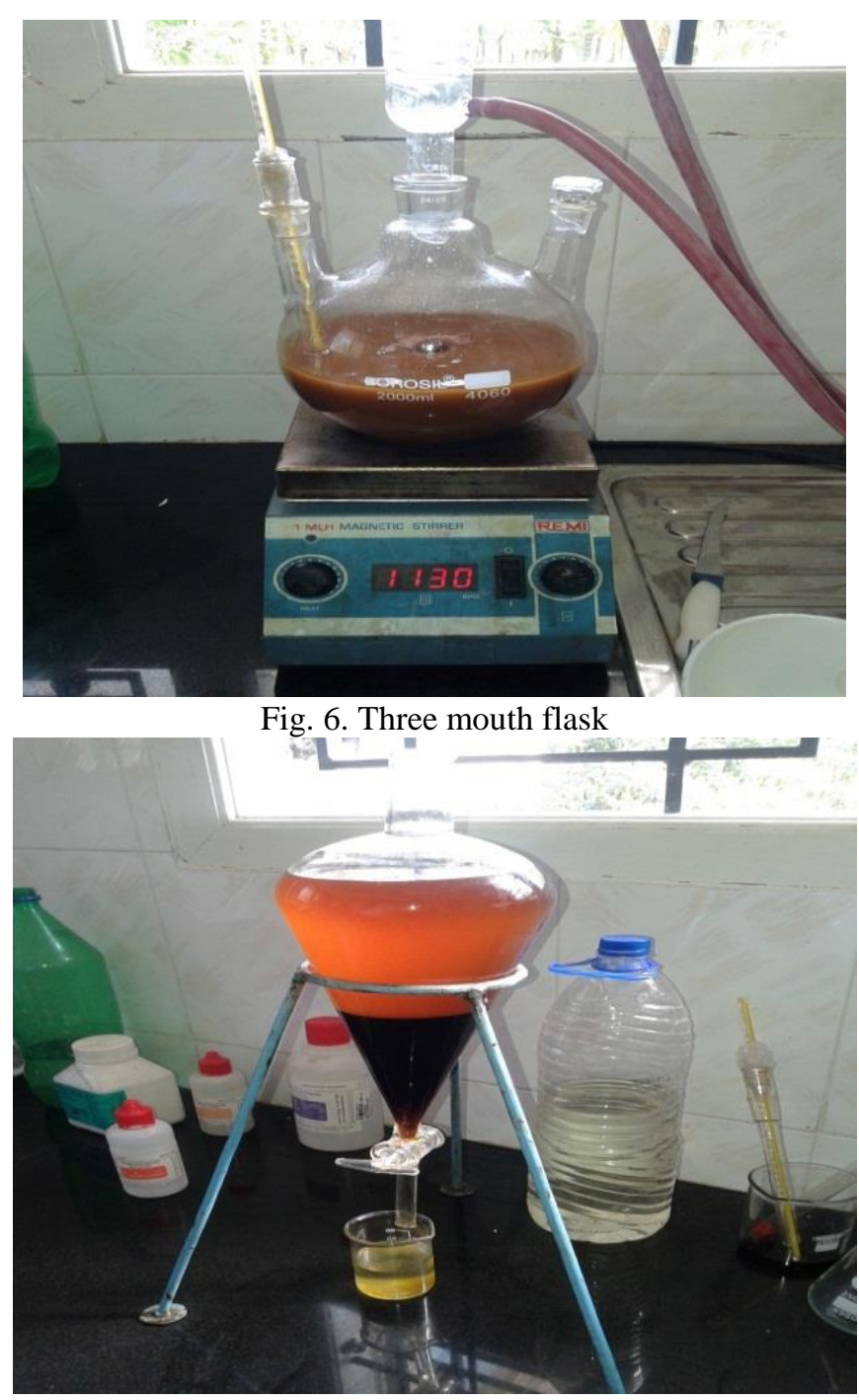

Fig. 7. Separation of glycerin and biodiesel

\subsection{Properties Of Fuels}

Table. 1. Properties of fuels

\begin{tabular}{|c|c|c|c|c|c|c|}
\hline Property & Diesel & $\begin{array}{c}\text { Karanja } \\
\mathbf{B 2 0}\end{array}$ & $\begin{array}{c}\text { Jatropha } \\
\mathbf{B 2 0}\end{array}$ & $\begin{array}{c}\text { Thevetia } \\
\mathbf{B 2 0}\end{array}$ & $\begin{array}{c}\text { Mahua } \\
\text { B20 }\end{array}$ & $\begin{array}{c}\text { Neem } \\
\mathbf{B 2 0}\end{array}$ \\
\hline Density $\left(\mathrm{kg} / \mathrm{m}^{3}\right)$ & 829 & 832 & 836 & 839 & 845 & 842 \\
\hline $\begin{array}{c}\text { Viscosity at } 40^{\circ} \mathrm{C} \\
(\mathrm{CSt})\end{array}$ & 3.52 & 3.61 & 3.74 & 3.96 & 4.06 & 4.01 \\
\hline Flash Point $\left({ }^{\circ} \mathrm{C}\right)$ & 53 & 59 & 69 & 77 & 82 & 79 \\
\hline Fire Point $\left({ }^{\circ} \mathrm{C}\right)$ & 59 & 64 & 76 & 86 & 91 & 89 \\
\hline $\begin{array}{c}\text { Calorific Value } \\
(\mathrm{MJ} / \mathrm{kg})\end{array}$ & 42.19 & 42.08 & 41.77 & 41.45 & 41.22 & 41.34 \\
\hline
\end{tabular}




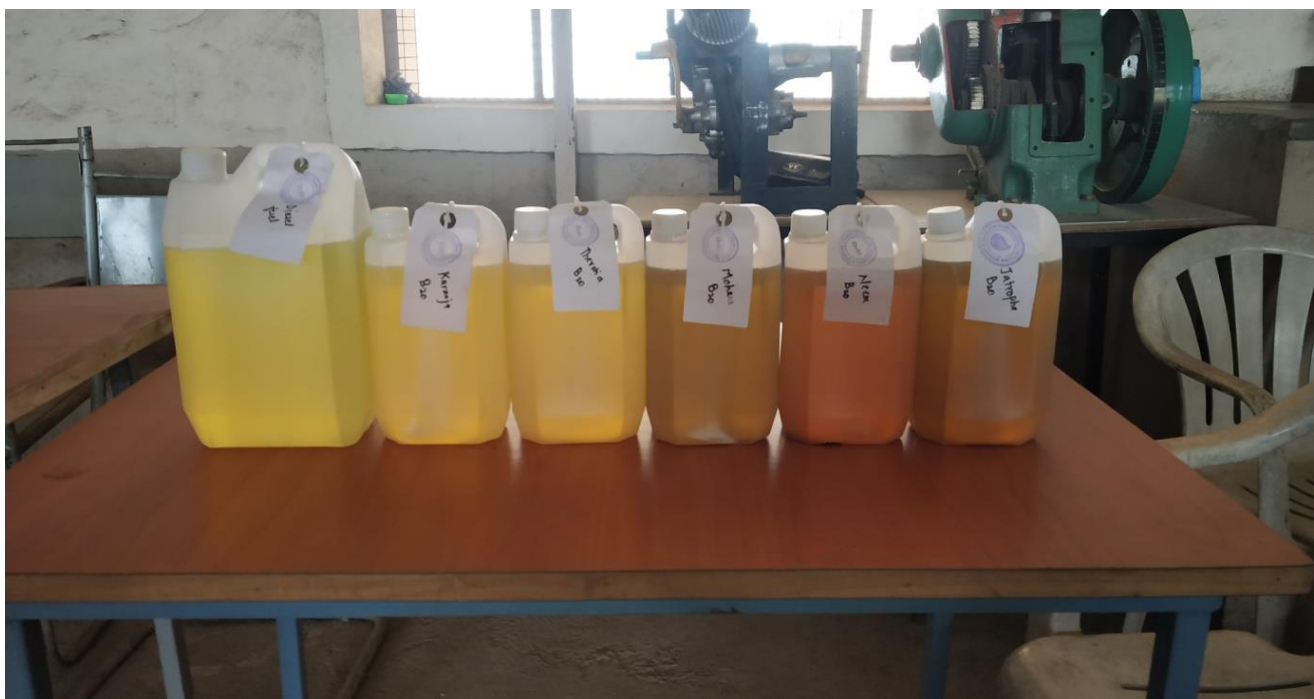

Fig. 8. Fuel samples used in project work

\section{EXPERIMENTAL SETUP}

A single cylinder, direct injection, fourstroke, water cooled, Compression Ignition (CI) engine is used in the experimental study. The fuel flow rate was measured by noting down the time taken for the consumption of a known quantity of fuel $(10 \mathrm{cc})$ from a burette. The viscosity of raw as well as esterified oil was measured by red wood viscometer, density by hydrometer, calorific value by bomb calorimeter, flash and fire point by open cup method. Initially, before starting experimental tests, the engine was made to run under ideal condition as warm up phase and then the tests were conducted. The engine was started and allowed to warm-up for about 10 minutes. The engine was tested under five discrete part load conditions i.e. $20 \%, 40 \%, 60 \%$, $80 \%$ and $100 \%$.

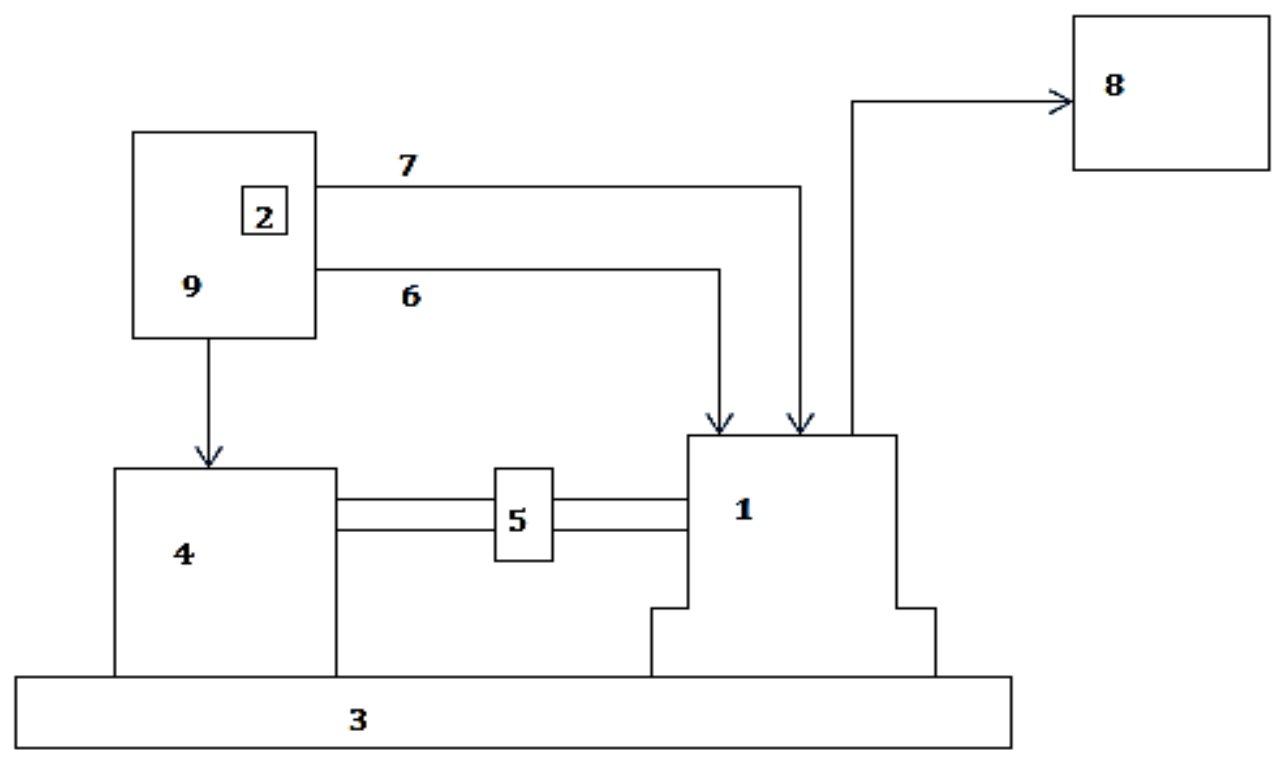

Fig. 9. Experimental Setup

1-Diesel engine, 2-Burette for fuel measurement, 3Base, 4-Dynamometer, 5-Coupling, 6-Air supply line, 7-Fuel supply line, 8-Exhaust gas analyzer, 9Control panel. 
International Journal of Research in Advent Technology, Vol.7, No.4, April 2019

E-ISSN: 2321-9637

Available online at www.ijrat.org

\subsection{Engine Specifications}

Table. 2. Engine parameters

\begin{tabular}{|l|l|}
\hline Engine Parameter & Specifications \\
\hline Engine Type & Kirloskar \\
\hline No. of Strokes & 4 \\
\hline No. of Cylinders & 1 \\
\hline Type of Cooling & Water Cooling \\
\hline Type of Injection & Direct Injection \\
\hline Bore & $87.5 \mathrm{~mm}$ \\
\hline Stroke & $110 \mathrm{~mm}$ \\
\hline Compression Ratio & $17.5: 1$ \\
\hline Rated Power & $5.2 \mathrm{~kW}$ \\
\hline Rated Speed & $1500 \mathrm{rpm}$ \\
\hline Injection Pressure & $210 \mathrm{bar}$ \\
\hline Injection Timing & $23^{\circ} \mathrm{BTDC}$ \\
\hline
\end{tabular}

\section{RESULTS AND DISCUSSION}

\subsection{Brake Thermal Efficiency}

For all the fuels tested the Brake Thermal Efficiency increases with increase in load. This is due to, reduction in heat loss and increase in power with increase in load. The Brake Thermal Efficiency of biodiesel was found to be lower compared to diesel at all power output. This is due to, the lower calorific value, higher viscosity, higher density which leads to poor atomization of biodiesel than diesel which results into increase of Brake Thermal Efficiency for diesel than biodiesel. At 80\% load condition all tested fuels give higher Brake Thermal Efficiency than at $100 \%$ load condition. This is due to the fact that, the power produced from the engine is less than the amount of fuel consumed to develop that power at $100 \%$ load condition so that Brake Thermal Efficiency decreases at $100 \%$ load condition as compared to $80 \%$ load condition.

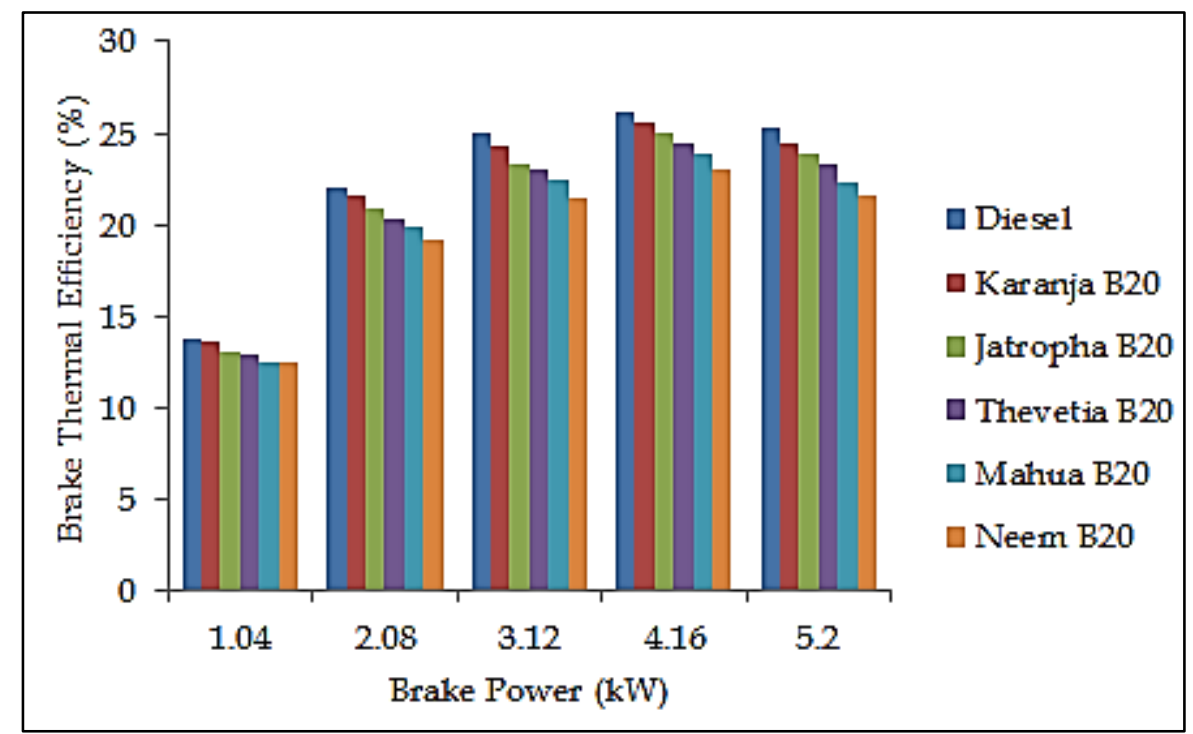

\subsection{Brake Specific Fuel Consumption}

Fig. 10. Variation of brake thermal efficiency with brake power

As the load increases Brake Specific Fuel Consumption decreases. It is observed that Brake Specific Fuel Consumption for biodiesel blends is higher when compared with diesel. For effective burning of the fuel the calorific value of the fuel should be higher so that the evaporation of the fuel is also high. The calorific values of blends of biodiesel are lower when compared with diesel; hence the fuel evaporation is slower. Slower evaporation rates leads to higher brake specific fuel consumption. 


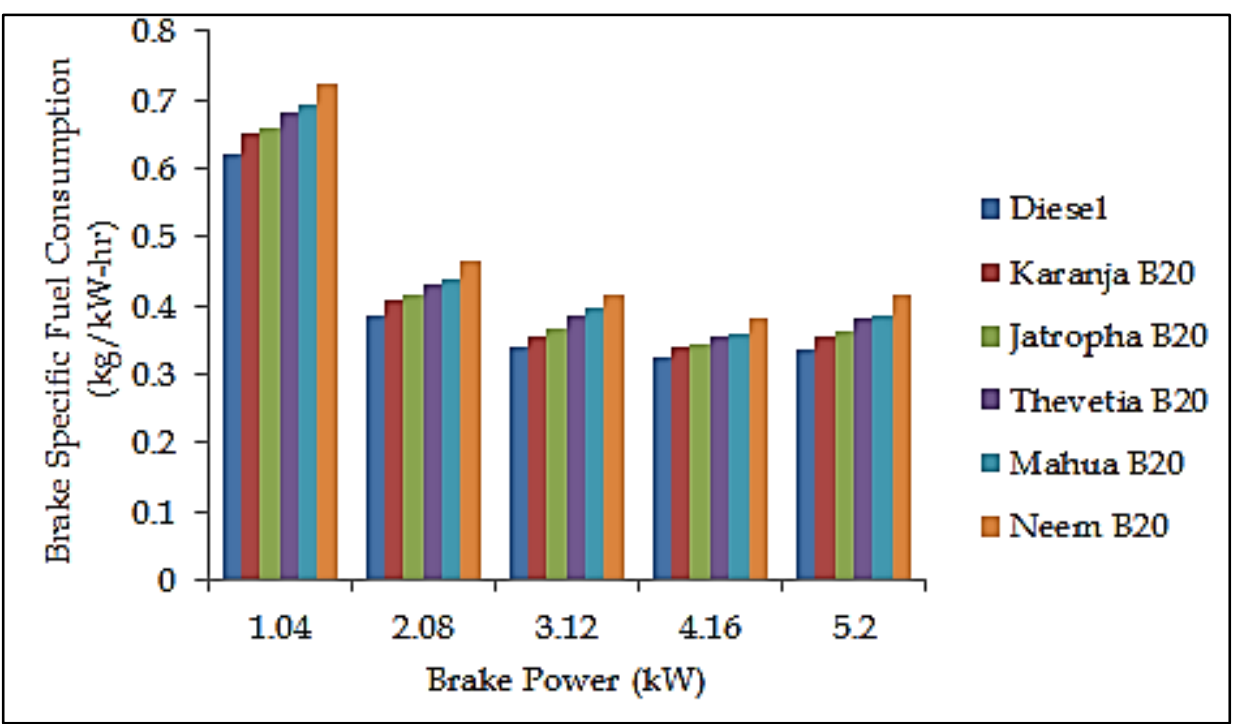

Fig. 11. Variation of Brake Specific Fuel Consumption with Brake Power

\subsection{Total Fuel Consumption}

biodiesel blends. This is due to higher viscosity,

As the load increases Total Fuel

Consumption increases for all fuels tested. Total Fuel

higher density which leads to higher fuel

Consumption for diesel is less as compared to consumption of biodiesel than diesel.

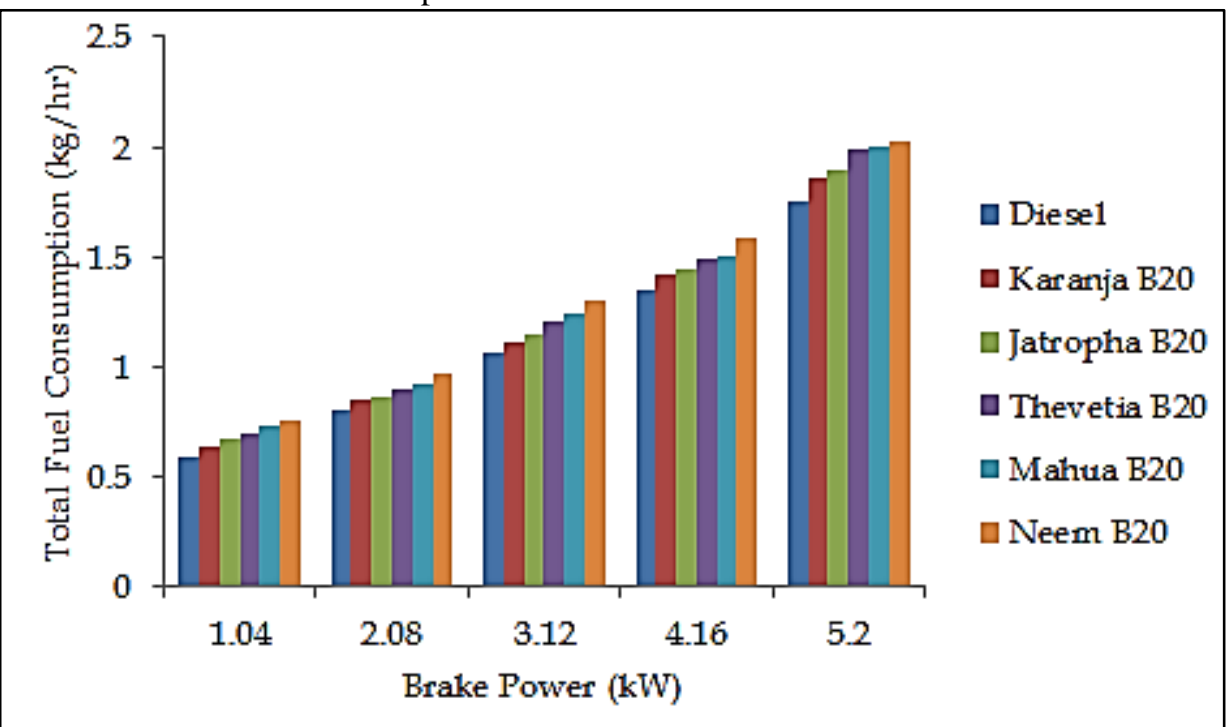

Fig. 12. Variation of Total Fuel Consumption with Brake Power

\subsection{Hydrocarbon Emissions}

The neat diesel exhibit lower amount of Hydrocarbon emissions as compared to biodiesel blends. This is mainly due to, higher viscosity of biodiesel blends which leads to poor mixing of fuel and air results into incomplete combustion. 


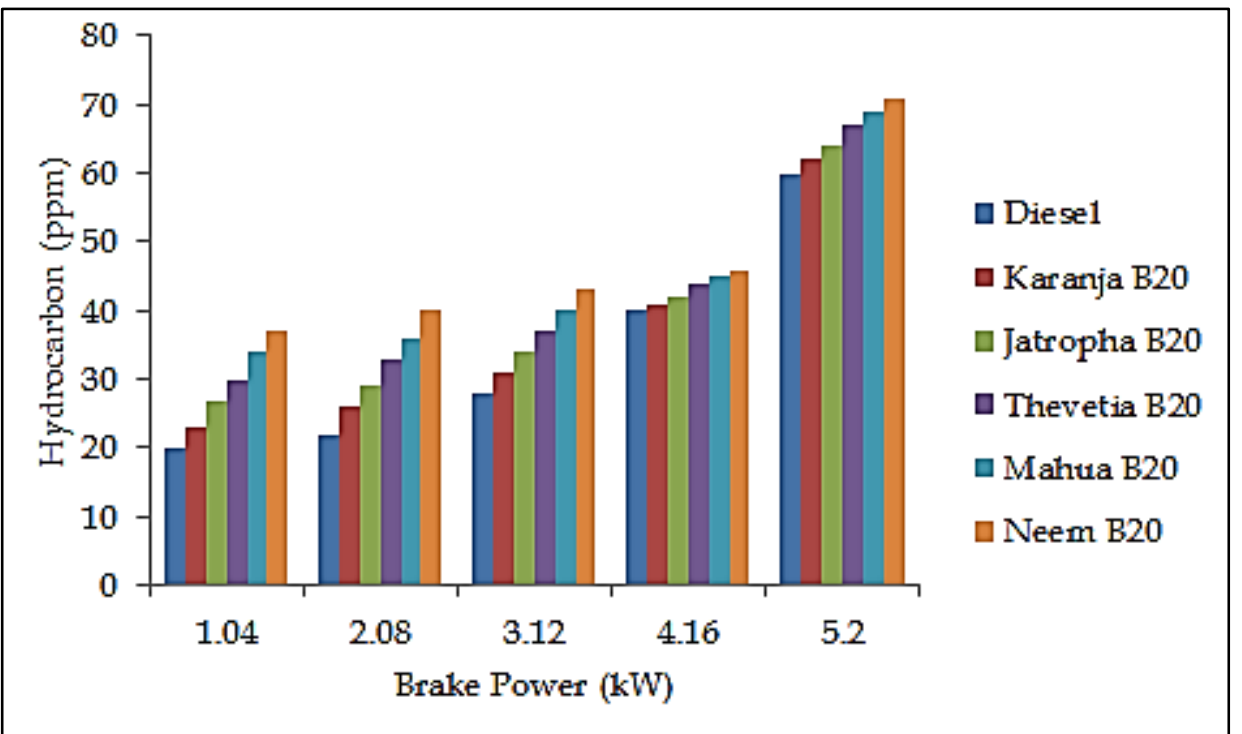

Fig. 13. Variation of Hydrocarbon emissions with Brake Power

\subsection{Carbon Monoxide Emissions}

The neat diesel exhibit lower amount of Carbon Monoxide emissions as compared to biodiesel blends. This is mainly due to, higher viscosity of biodiesel blends which leads to poor mixing of fuel and air results into incomplete combustion.

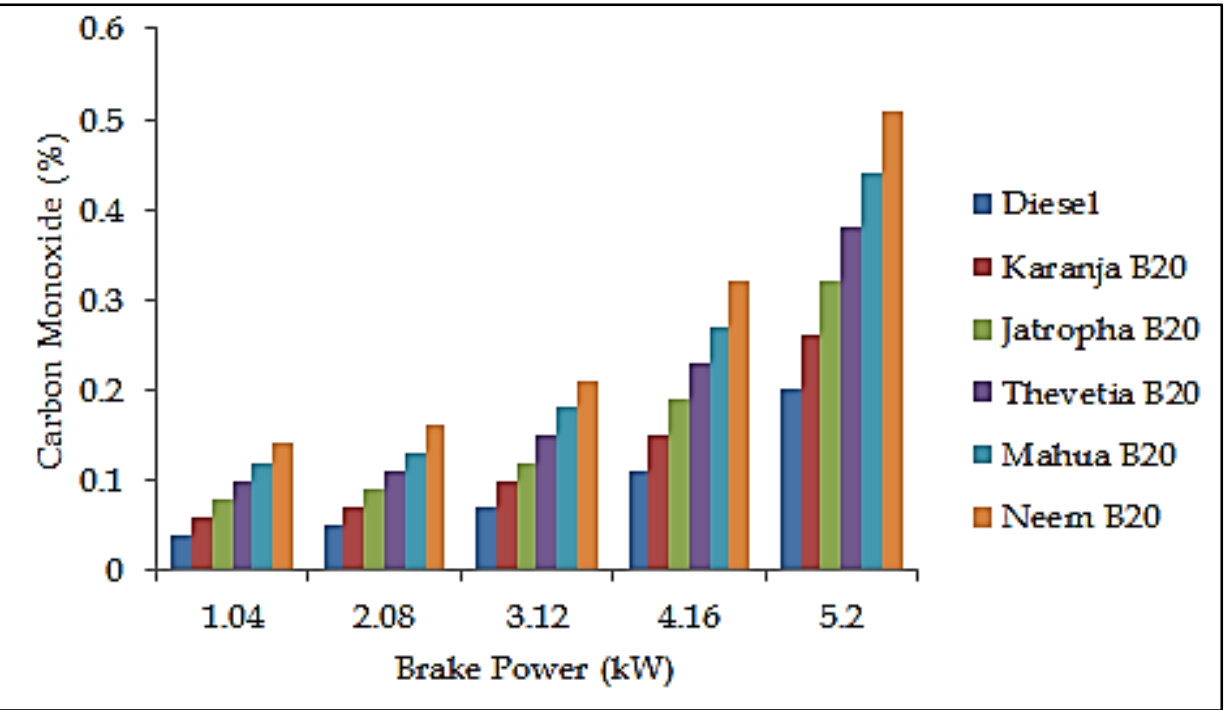

Fig. 14. Variation of Carbon Monoxide emissions with Brake Power

\subsection{Nitric Oxide Emissions}

The neat diesel exhibit higher amount of Nitrogen Oxide emissions as compared to biodiesel blends. This is mainly due to, diesel having higher calorific value and lower viscosity than biodiesel blends. This results into better mixing of fuel and air which leads into complete combustion of fuel. The complete combustion of fuel results higher Peak Pressure Rise rate and higher Exhaust Gas Temperature which leads to higher value of Nitrogen Oxide emissions than biodiesel blends. 


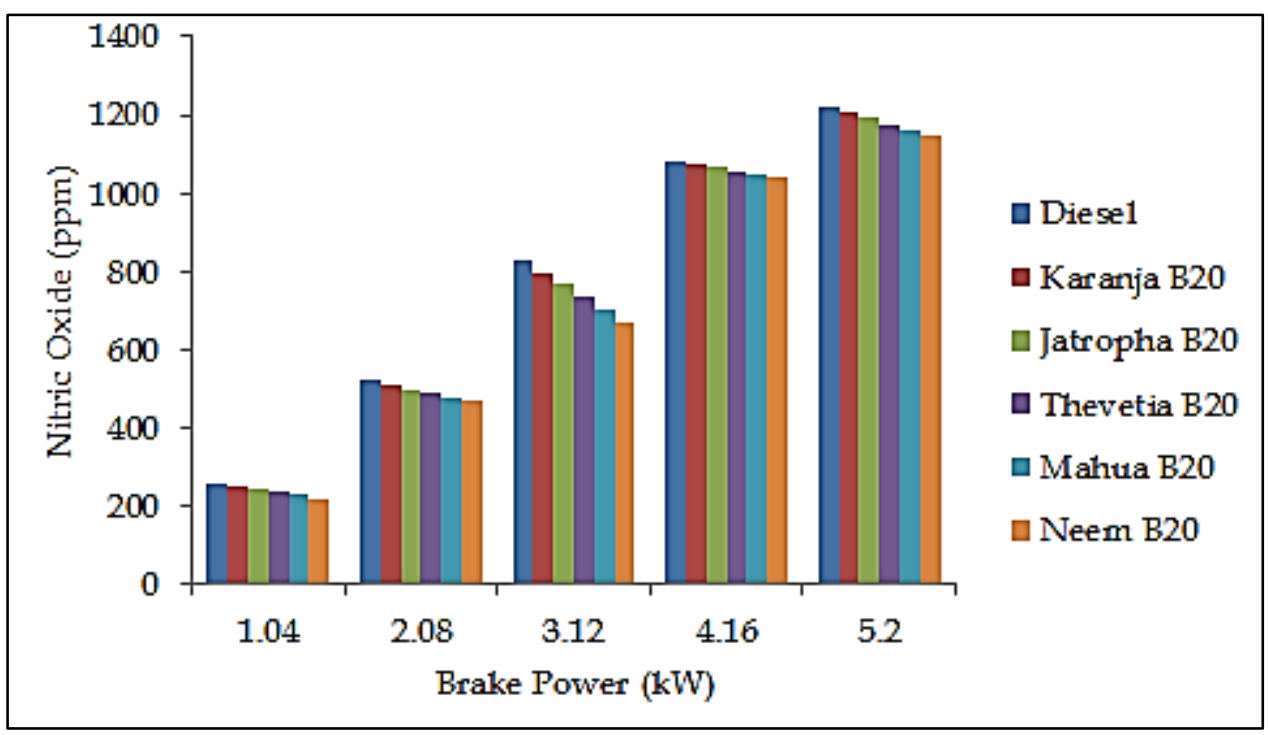

Fig. 15. Variation of Nitric Oxide emissions with Brake Power

\section{PROJECT OUTPUT}

* Jatropha B20, Thevetia Peruviana B20, Karanja B20, Mahua B20, Neem B20 blends can be successfully used in diesel engines.

* All B20 blends can partially replace for diesel fuel successfully.

* By varying different B20 blends we get Karanja B20 blend as optimized blend for diesel engine.

6. CONCLUSIONS

* The Brake Thermal Efficiency of Karanja B20 blend is $25.52 \%$ which is higher as compared to other biodiesel blends.

* Total Fuel Consumption for Karanja B20 blend is $1.86 \mathrm{~kg} / \mathrm{hr}$ which is lower as compared to other biodiesel blends.

* Brake Specific Fuel Consumption for Karanja B20 blend is $0.341 \mathrm{~kg} / \mathrm{kW}-\mathrm{hr}$ which is lower as compared to other biodiesel blends.

* The Karanja B20 blend exhibit lower amount of Hydrocarbon emissions $63 \mathrm{ppm}$ as compared to other biodiesel blends.

* The Karanja B20 blend exhibit lower amount of Carbon Monoxide emissions $0.26 \%$ as compared to biodiesel blends.

* The Karanja B20 blend exhibit higher amount of Nitrogen Oxide emissions 1205 ppm as compared to biodiesel blends.

* Among the biodiesel blends tested, Karanja B20 gave the best performance with reduced emissions.

\section{REFERENCES}

[1] R.K.Yadav, S.L.Sinha, "Performance of Diesel Engine Using Blends of Conventional Diesel and Jatropha Biodiesel as Alternative Fuel for Clean Environment", International Journal for Research in Emerging Science and Technology, 2015, 2(2), 8-15.

[2] M.Venkatraman, G.Devaradjane, "Performance and Exhaust Emissions of a Low Heat Rejection Diesel Engine Using Jatropha Oil as Fuel", Journal of Chemical and Pharmaceutical Research, 2014, 6(11), 561-569.

[3] V.R.Mamilla, M.V.Mallikarjun, G.L.Rao, "Effect of Combustion Chamber Design on a DI Diesel Engine Fuelled with Jatropha Methyl Esters Blends with Diesel", Procedia Engineering, 2013, 64, 479-490.

[4] A.Agarwal, M.K.Singh, "Process Optimization for Biodiesel Production from Jatropha Oil and its Performance Evaluation in a CI Engine", International Journal of Latest Trends in Engineering and Technology, 2012, 1(4), 65-72.

[5] M.Venkatesan, "Effect of Injection Timing and Injection Pressure on a Single Cylinder Diesel Engine for Better Performance and Emission Characteristics for Jatropha Biodiesel in Single and Dual Fuel Mode with CNG", International Journal of Advances in Engineering and Technology, 2013, 6(1), 21-34.

[6] S.M.A.Ibrahim, K.A.Abed, M.S.Gad, "An Experimental Investigation of Diesel Engine 


\section{E-ISSN: 2321-9637}

\section{Available online at www.ijrat.org}

Performance Using Jatropha Biodiesel", World Applied Sciences Journal 2014, 31(6), 998-1003.

[7] P.Suresh, R.K.Donga, P.K.Sahoo, "Experimental Comparative Study Between Performance and Emissions of Jatropha Biodiesel and Diesel Under Varying Injection Pressures", International Journal of Engineering Sciences and Emerging Technologies, 2012, 3(1), 98-112.

[8] T.V.Rao, G.P.Rao, K.H.C.Reddy, "Experimental Investigation of Pongamia, Jatropha and Neem Methyl Esters as Biodiesel on CI Engine", Jordan Journal of Mechanical and Industrial Engineering, 2008, 2(2), 117-122.
[9] S.Pandey, A.Sharma, P.K.Sahoo, "Experimental Investigation on the Performance and Emission Characteristics of a Diesel Engine Fuelled with Ethanol, Diesel and Jatropha based Biodiesel Blends", International Journal of Advances in Engineering and Technology, 2012, 4(2), 341353.

[10] A.Murali, B.Xavier, K.P.Jaseel, A.T.Antony, T.Moideen, D.Viswajith, K.Ranjith, "Experimental Investigation on Performance Characteristics of Diesel Engine Operated on Jatropha Biodiesel with LPG Jet Induction", Proceedings of $5^{\text {th }}$ IRF International Conference, Chennai, $23^{\text {rd }}$ March. 2014, Pages 32-35. 